\title{
The optimization model on the temperature of a bathtub
}

\author{
Binbin Ghen ${ }^{1, * a}$ \\ ${ }^{1}$ School of Automation, North China Electric Power University, Baoding 071000, China. \\ azj_lh_cbb@163.com
}

Keywords: optimization model, bathtub, temperature.

\begin{abstract}
It is always a challenge for us to maintain the temperature throughout the bath water. To solve this disturbing problem, we set up two models to deal with the problem.The first model, called the water adding model based on the uniform temperature distribution, is set mainly about finding out the best strategy with the bather moving regularly. In this part, we only consider heat dissipation around the bathtub and heat exchange with the hot water. Then we figure out a set of optimization equations. And in the end, we also explain the relationship between the factors we consider with our strategy, such as the shape of the bathtub, the size of the use, the intensity of bather's movement and the effect the bubble bath additive makes. After analysis of the model with the bather moving, we present the water adding model based on the uneven temperature distribution, aimed at finding the best strategy with the bather sitting or lying.In all, we get the conclusion that with the hot water going down, a specific bather in a specific bathtub can adopt a specific hot water tap's opening with a specific temperature.
\end{abstract}

\section{Introduction}

In this paper, we suppose that a virtual character is here, ready to take a bath. After the man fills a bathtub with hot water from a single faucet, he settles into the bathtub to cleanse and relax. At this time, the temperature is the most comfortable to the man. But with the time going on, the bath water is getting noticeably cooler. To make the water go back to the initial suitable temperature, the bather adds a constant trickle of hot water from the faucet. And one thing is also important that the bathtub has its capacity and excess water can escape through an overflow drain.

So, here, we are required to build a model of temperature of the bathtub water in space and time to determine the best strategy. The main purpose is that the bather can keep the temperature as close as possible to the initial temperature, as well as throughout the bathtub. And the next target for us is to determine the extent to which our strategy depends on some factors with our model, such as the size of the tub and the bather. Besides, we shall consider a special circumstance that the bather take a bath with a bubble bath additive.

\section{Analysing and Modelling}

\subsection{Assumptions}

The strategy we shall consider is nearly hard to find. So, to simplify the problem, here, we give out some more basic assumptions that are only essential in this part.

- We assume that the movement of the bather obeys the regulation of sines. Generally speaking, only the arms and legs are swigging while taking a bath. And the trend is just like the regulation of sines.

- This model we established is about a heat transfer model with the uniform temperature distribution. In this model, the bather is assumed to move through the tub, which makes the water's temperature become uniform more quickly.

- We assume that the temperature is only function of time. According to the first assumption above, we can know that the temperature doesn't vary in space. It is the same wherever it is.

- The bubble bath additive is uniform over the water surface. The density of the bubble bath additive is less than that of the water. And in a short time, it will cover the whole surface. 


\subsection{Model establishment}

When the bath water is getting colder, the hot water is put down. And the water begins to transfer the heat. As the hot water gets into the tub, some of the relatively cold original water is squeezed out from the tub. In this process, the water squeezed out from the tub doesn't exchange heat with the hot water and the rest water in the tub take quite little time to be mixed with hot water to reach new temperature. And we give the following sketch map.

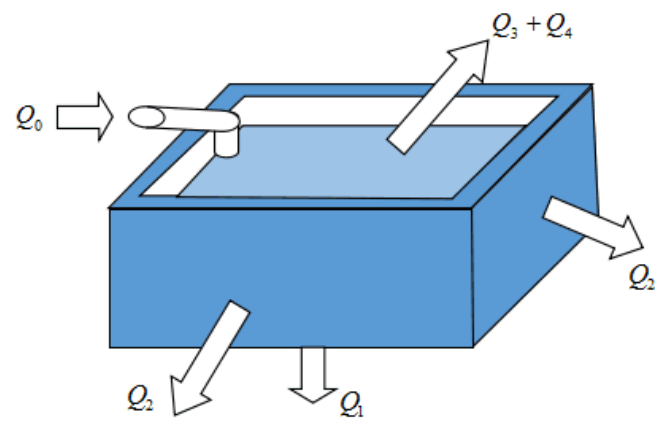

Fig.1 Sketch map on the heat exchange around the bath

According to the first law of thermodynamics, we can get the following formula in the time period from $t$ to $t+\Delta t$.

$$
\rho v_{1} s_{1} c \Delta t\left(T_{1}-T(t)\right)=\rho\left(V_{0}-v_{1} s_{1} \Delta t\right)(T(t+\Delta t)-T(t))+Q \cdot \Delta t+W \cdot \Delta t
$$

In the formula (1) above, $\boldsymbol{V}_{\mathbf{0}}$ means the volume of the water in the bathtub. $Q$ means heat dissipating capacity. It includes heat conduction of bottom surface of bathtub

heat conduction of side surface of bathtub

$$
Q_{1}=\frac{\lambda_{1}}{\delta_{1}} S_{1}\left(T(t)-T_{b}\right)
$$

$$
Q_{2}=\left(\frac{\lambda_{2}}{\delta_{2}}+\alpha_{1}+\alpha_{2}\right) S_{2}\left(T(t)-T_{s}\right)
$$

and convective heat transfer on water surface

$$
Q_{3}=h S_{3}\left(T(t)-T_{s}\right) .
$$

We also give out a sketch map on side surface of the bathtub

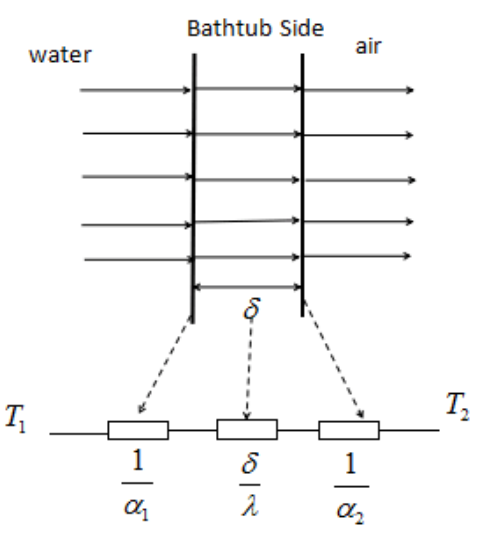

Fig.2 Sketch map on side surface of the bathtub

Besides, evaporative cooling is

$$
Q_{4}=\beta S_{3}\left(P_{v} "-P_{v}\right) .
$$

$P_{\mathrm{v}}$ " means the steam pressure of thin saturated layer of water surface. $P_{v}$ means water vapor pressure in wet air. And $\beta$ follows[2]

$$
\beta=\left[22.0+2.0\left(\mathrm{~T}-\mathrm{T}_{\mathrm{s}}\right)\right] .
$$

The total heat dissipating capacity[3] is 


$$
Q=Q_{1}+Q_{2}+Q_{3}+Q_{4}
$$

However, if we consider the situation that the bather take a bath with a bubble bath additive, formula (4) and (5) will be changed into

$$
Q_{3+4}=\frac{\lambda_{3}}{\delta_{3}} S_{3}\left(T(t)-T_{s}\right)
$$

Also heat dissipation due to human disturbance is

$$
\boldsymbol{W}=\boldsymbol{A}+\boldsymbol{B} \cdot \sin (\boldsymbol{t}) \text {. }
$$

$B$ reflects the intensity of the disturbance. Here, convective heat transfer coefficient is

$$
\begin{gathered}
h=h^{\prime}+\Delta h, \\
\Delta h=K B .
\end{gathered}
$$

And two more important indexes are water consumption

$$
V=v_{1} s_{1} t
$$

and energy consumption

$$
Q_{0}=\rho c V\left(T_{1}-T_{a}\right)
$$

Our main target is to make the mixed water's temperature as close as the initial one with the minimum amount of the hot water and the energy consumption. And combined with the constrain conditions, we can get

$$
\text { s.t. }\left\{\begin{array}{c}
Q_{0}, \min \quad V \\
T=T_{0} \\
t_{s} \leq \frac{1}{10} t_{0} \\
0<v_{1} s_{1}<q_{\max } \\
T_{1} \leq T_{1 \max }
\end{array}\right. \text {. }
$$

And if we change the bathtub's shape, the areas in formulas (1) (5) are different and the best strategy is also changed. If we change the bather's shape, the areas in these formulas are also different. And in that way, we can get an another best strategy. In calculation, we use the data from the reality.

\section{Results}

Results and comparison After computing these formulas above, we can get the following best condition. And the main indexes are the input water flow, the input water temperature and the final mixed water temperature.

- When we consider the shape of the bathtub, we can get the following charts below after calculating formula (15). And the results are as follows:

Table 1 The best condition with the tub in the shape of rectangular block

\begin{tabular}{|c|c|c|c|}
\hline $\begin{array}{c}\text { the inlet } \\
\text { velocity } \\
/ \boldsymbol{m} \cdot \boldsymbol{s}^{-1}\end{array}$ & $\begin{array}{c}\text { The opening of the } \\
\text { water tab } \\
\%\end{array}$ & $\begin{array}{c}\text { the input water } \\
\text { temperature } \\
{ }^{\circ} \mathrm{C}\end{array}$ & $\begin{array}{c}\text { the final mixed water } \\
\text { temperature } \\
{ }^{\circ} \mathrm{C}\end{array}$ \\
\hline 0.1100 & 37 & 97 & 39.0441 \\
\hline
\end{tabular}

Table 2 The best condition with the tub in the shape of cylinder

\begin{tabular}{|c|c|c|c|}
\hline $\begin{array}{c}\text { the inlet } \\
\text { velocity } \\
/ \mathbf{m} \cdot \mathbf{s}^{-1}\end{array}$ & $\begin{array}{c}\text { The opening of the } \\
\text { water tab } \\
\%\end{array}$ & $\begin{array}{c}\text { the input water } \\
\text { temperature } \\
{ }^{\circ} \mathrm{C}\end{array}$ & $\begin{array}{c}\text { the final mixed water } \\
\text { temperature } \\
{ }^{\circ} \mathrm{C}\end{array}$ \\
\hline 0.2900 & 97 & 98 & 39.0121 \\
\hline
\end{tabular}


Table 3 The best condition with the tub in the shape of frustum of a cone

\begin{tabular}{|c|c|c|c|}
\hline $\begin{array}{c}\text { the inlet } \\
\text { velocity } \\
/ \boldsymbol{m} \cdot \boldsymbol{s}^{-1}\end{array}$ & $\begin{array}{c}\text { The opening of the } \\
\text { water tab } \\
\%\end{array}$ & $\begin{array}{c}\text { the input water } \\
\text { temperature } \\
{ }^{\circ} \mathrm{C}\end{array}$ & $\begin{array}{c}\text { the final mixed water } \\
\text { temperature } \\
{ }^{\circ} \mathrm{C}\end{array}$ \\
\hline 0.1800 & 60 & 97 & 39.0258 \\
\hline
\end{tabular}

As is shown in the tables above, different kinds of bathtub shapes make a major influence on the best decision on the opening of the input water tap, which definitely affect the inlet velocity. But the input water temperature is nearly not changed. And the final mixed water temperature is nearly the $37^{\circ} \mathrm{C}$, which reaches the most comfortable temperature to the bather.

Table 4 The best condition with the bubble bath additive in the shape of rectangular block

\begin{tabular}{|c|c|c|c|}
\hline $\begin{array}{c}\text { the inlet } \\
\text { velocity } \\
/ \boldsymbol{m} \cdot \boldsymbol{s}^{-1}\end{array}$ & $\begin{array}{c}\text { The opening of the } \\
\text { water tab } \\
\%\end{array}$ & $\begin{array}{c}\text { the input water } \\
\text { temperature } \\
{ }^{\circ} \mathrm{C}\end{array}$ & $\begin{array}{c}\text { the final mixed water } \\
\text { temperature } \\
{ }^{\circ} \mathrm{C}\end{array}$ \\
\hline 0.10 & 33.3 & 96 & 39.044 \\
\hline
\end{tabular}

Compared with the results presented above, the inlet velocity and the input water temperature decrease. And from this, w can get that the bubble bath additive have the function of keeping the temperature.

\section{Summary}

In this paper, we establish two models to consider the best strategy. Model I is about finding the best strategy with the bather moving and Model II is aimed at finding the best strategy with the bather sitting or lying. And finally we use the data from the reality to get the results. Our main indexes are the input water flow, the input water temperature and the final mixed water temperature. By estimating these indexes, we can compare the best strategies in different situations.

Concluding these two models, there is a general word: we should increase the input water temperature and decrease the water flow, depending on the situation, in order to achieve the best goal. In our model results, different bathtub shapes and the bather's weight result in different best strategy. Take this for example. If the bather, weighted $60 \mathrm{~kg}$, moving throughout the bathtub, take a bath in the rectangular block tub, we get the best strategy: the tap's opening is $37 \%$ and the hot water temperature is about $97^{\circ} \mathrm{C}$. And the tap's opening varies with the shape of the bathtub and the temperature relates closely to the weight of the bather. Besides, we know that a bubble bath additive mainly affects both of them, which makes the tap's opening less and the temperature needed lower. Also, we draw a conclusion that the movement carried by the bather makes effect on the input water temperature and nearly has no influence on the opening of the hot water tap.After the analysis of these results, we test our second model by using the professional software and determine that our model is believable.

Our overall model successfully accomplishes the target to find the best strategy in the introduction section. And we find out different strategies for different bathers. Though our model has advantages, we must realize that there are still some left to improve, such as the joint effect on the bathtub's shape, the bather's size and the bather's motions.

\section{References}

[1] Pei Yu, Changqi Yan, Haifeng Gu, Wei Chen. Analysis of steady state temperature field without perturbation in density lock[J]. Nuclear power engineering. 2010, 01:38-41+48.

[2] Zhenguo Zhou. Discussion on water surface evaporation coefficient formula[J]. Journal of hydraulic engineering, 2009, 12:1440-1443.

[3] Jianpu Li. Fast calculation of temperature field[D]. Shanghai Normal University, 2010. 